\title{
Lose Pain, Lose Weight, and Lose Both: A Cohort Study of Patients with Chronic Pain and Obesity Using a National Quality Registry
}

\author{
Huan-ji Dong (D) \\ Elena Dragioti (D) \\ Marcelo Rivano Fischer ${ }^{2,3}$ \\ Björn Gerdle $\mathbb{D}^{\prime}$
}

'Pain and Rehabilitation Centre, Department of Health, Medicine and Caring Sciences, Linköping University, Linköping, Sweden; ${ }^{2}$ Department of Health Sciences, Research Group Rehabilitation Medicine, Lund University, Lund, Sweden; ${ }^{3}$ Department of

Neurosurgery and Pain Rehabilitation,

Skåne University Hospital, Lund, Sweden
Background: It is known that chronic pain makes it difficult to lose weight, but it is unknown whether obese patients (body mass index $\geq 30 \mathrm{~kg} / \mathrm{m}^{2}$ ) who experience significant pain relief after interdisciplinary multimodal pain rehabilitation (IMMPR) lose weight.

Objective: This study investigated whether obese patients with chronic pain lost weight after completing IMMPR in specialist pain units. The association of pain relief and weight change over time was also examined.

Methods: Data from obese patients included in the Swedish Quality Registry for Pain Rehabilitation for specialized pain units were used $(\mathrm{N}=224)$, including baseline and 12month follow-up after IMMPR from 2016 to 2018. Patients reported body weight and height, pain aspects (eg, pain intensity), physical activity behaviours, psychological distress, and health-related quality of life (HRQoL). A reduction of at least $5 \%$ of initial weight indicates clinically significant weight loss. Patients were classified into three groups based on the pain relief levels after IMMPR: pain relief of clinical significance $(30 \%$ or more reduction of pain intensity); pain relief without clinical significance (less than $30 \%$ reduction of pain intensity); and no pain relief. Linear mixed regression models were used to examine the weight changes among the groups with different pain relief levels.

Results: A significant reduction of pain intensity was found after IMMPR $(p<0.01$, effect size Cohen's $d=0.34$ ). A similar proportion of patients in the three groups with different pain relief levels had clinically significant weight loss $(20.2 \% \sim 24.3 \%, p=0.47)$. Significant improvements were reported regarding physical activity behaviour, psychological distress, and HRQoL, but weight change was not associated with changes of pain intensity.

Conclusion: About one-fifth of obese patients achieved significant weight reduction after IMMPR. Obese patients need a tailored pain rehabilitation program incorporating a targeted approach for weight management.

Keywords: obesity, weight loss, chronic pain, pain intensity, pain rehabilitation

\section{Introduction}

Pain and obesity are common comorbidities. ${ }^{1,2}$ Weight management programs have found that pain-related inhibition interferes with weight loss interventions. ${ }^{3-6}$ Obesity appears to be a potential marker of functional and psychological complications of chronic pain. ${ }^{7}$ The vicious cycle of pain-inactivity-weight gain-more pain related to obesity has also been identified as a difficult challenge in pain rehabilitation. ${ }^{8,9}$ Daily clinical practice, especially in specialist units of multidisciplinary pain rehabilitation, often focuses on interventions that address chronic pain
Correspondence: Huan-Ji Dong

Pain and Rehabilitation Centre,

Department of Health, Medicine and

Caring Sciences, Linköping University,

Linköping, SE-58I 85, Sweden

Tel +46730488933

Email huanji.dong@liu.se 
and other common comorbidities such as anxiety, depression, and sleep deprivation. However, weight reduction for obese patients with chronic pain is not considered a primary goal. Typically, health professionals and patients expect that other comorbidities can be treated simultaneously after one major problem - eg, chronic pain - has improved.

Interdisciplinary multimodal pain rehabilitation (IMMPR) includes group activities (eg, chronic pain education, supervised physical activity, cognitive behavioural therapy, and work and activity training) led by health professionals over several weeks to a few months. ${ }^{10,11}$ As with interventions in weight management, IMMPRs are delivered by an interdisciplinary team working according to a biopsychosocial framework. ${ }^{12,13}$

Earlier studies report that pain rehabilitation increases weight loss and reduces pain in overweight/obese patients who have knee osteoarthritis. ${ }^{6,14}$ However, these studies were limited to specific pain conditions and pain reduction was not considered clinically important. ${ }^{15}$ As obesity is related to several pain conditions, it is worth studying the impact of IMMPR on obese patients with various pain conditions. Since 2016, the Swedish Quality Registry for Pain Rehabilitation (SQRP) has included self-reported body weight and height, data that reflect Sweden's increased attention on obesity and pain. To understand how pain and weight control are related, it is also important to compare outcomes from patients with different pain conditions undergoing IMMPR to outcomes from weight management services. This study investigates whether obese patients presenting a variety of chronic pain conditions reduced their weight after completing an IMMPR in specialist pain units. As there are bilateral barriers between pain relief and weight reduction, ${ }^{4,5,16}$ this study also evaluates the influences of pain relief on weight change over time. Increased knowledge about whether obese patients can obtain weight loss benefits from IMMPR may help improve IMMPR interventions for this specific and growing patient group.

\section{Materials and Methods}

\section{Study Sample and Procedure}

This study used data from the Swedish Quality Registry for Pain Rehabilitation (SQRP). Most Swedish pain units $(>90 \%)$ refer to data from this registry to assess patients and to develop interdisciplinary rehabilitation strategies. The SQRP and the instruments included have been described in detail elsewhere. ${ }^{10,11}$ Briefly, specialist pain units handle patients with complex chronic pain referred mainly by primary care physicians. Inclusion criteria were patients $\geq 18$ years old with disabling chronic musculoskeletal pain ( $\geq 3$ months), defined as non-malignant pain conditions such as back or neck pain and fibromyalgia or general widespread pain. For this study, we obtained SQRP data from two consecutive years, between 2016 and 2018, for subjects with additional comorbid obesity (Body Mass Index, BMI $\geq 30 \mathrm{~kg} / \mathrm{m}^{2}$ ). The patients complete the SQRP questionnaires (see below) before their first visit (Pre-IMMPR), immediately after completing the IMMPR (between 4 and 18 weeks), ${ }^{17}$ and at a 12 month follow-up (FU-IMMPR). In this study, we used data from the Pre-IMMPR and FU-IMMPR to measure the maintained effect of weight changes. Exclusion criteria were ongoing major somatic or psychiatric disease, a history of significant substance abuse, or a state of acute crisis. Diseases that did not allow physical exercise and specific pain conditions with other treatment options available (red flags) were general exclusion criteria.

MMRP distinguishes itself as a well-coordinated intervention leading to a complex intervention instead of a single treatment. The MMRPs continue over a lengthy period with a common goal and generally include education, supervised physical activity, training in simulated environments, and cognitive behavioural therapy (CBT) coordinated by an interdisciplinary team (eg, physician, occupational therapist, physiotherapist, and psychologist) using a biopsychosocial view of chronic pain. ${ }^{17,18}$ IMMPR programs in specialist units are conducted in groups of six to eight patients. Each patient makes an individual plan and a schedule in collaboration with the IMMPR team. Systematic reviews have reported that IMMPRs are more effective than single treatment or treatment-as-usual programs. ${ }^{18-20}$

This study was conducted in accordance with the Helsinki Declaration and Good Clinical Practice and approved by the Ethical Review Board in Linköping (Dnr: 2015/108-31). Signed informed consent forms were collected from all participants.

\section{Measurement}

\section{Background Variables}

Self-administered SQRP questionnaires provided the socio-demographic information: age (years), gender (male/female), highest education level (college/university, secondary school, or primary school), country of birth 
(Nordic countries or Non-Nordic countries), and working or studying (yes/no).

\section{Weight Status and Weight Changes}

This study included all the participants classified as obese at the Pre-IMMPR according to the World Health Organization (WHO) criteria: obesity class I (BMI $30-34.9 \mathrm{~kg} / \mathrm{m}^{2}$ ); obesity class II (BMI $\geq 35-39.9 \mathrm{~kg} / \mathrm{m}^{2}$ ); and obesity class III (BMI $\left.\geq 40 \mathrm{~kg} / \mathrm{m}^{2}\right){ }^{21}$ Body weight and height were self-reported or measured at the unit and registered during the clinical assessment. Weight change (Pre-IMMPR vs FU-IMMPR) is defined as weight loss of $\geq 5 \%$ of initial body weight (at PreIMMPR), weight stable with no more than 5\% weight reduction or gain, and weight gain with an increase of $>5 \%$ of body weight. $^{5,22,23}$ A reduction of at least $5 \%$ of initial weight indicated clinically meaningful weight loss after one year of treatment. 23,24

Previous studies have found high correlations between measured weight- and height-calculated BMI and selfreported values of BMI (Pearson's $r=0.89-0.97$ for different age groups and gender). ${ }^{25}$ Self-reported values (sensitivity of $88.1 \%$ and specificity of $97.4 \%$ ) are used to identify overweight/obesity based on BMI measurements. ${ }^{26}$

\section{Pain and Changes of Pain Intensity}

A Numeric Rating Scale (NRS) was used to rate average pain intensity for the previous week, with a possible score from 0 to 10 where the highest number represents the worst possible pain. This variable is denoted as NRS-7d. Although no definitive meaningful pain relief exists, changes in pain intensity (pre-IMMPR vs FU-IMMPR) were grouped into three categories following the criteria that a $30 \%$ or more reduction in NRS is considered a clinically important difference. ${ }^{5,27}$ A minimal important reduction was considered as a one point NRS reduction or 10-20\% NRS reduction, a limit found in the literature. ${ }^{28,29}$ This resulted in the following three categories: pain relief $\geq 30 \%$ NRS decrease, pain relief $<30 \%$ NRS decrease, and no pain relief (no NRS change or increased NRS at FU-IMMPR).

Pain distribution (Pain Region Index, PRI) reflects the degree of anatomical spread of pain on the body. PRI was obtained using 36 predefined anatomical areas (18 on the front and 18 on the back of the body): (1) head/face, (2) neck, (3) shoulder, (4) upper arm, (5) elbow, (6) forearm, (7) hand, (8) anterior aspect of chest, (9) lateral aspect of chest, (10) belly, (11) sexual organs, (12) upper back, (13) low back, (14) hip/gluteal area, (15) thigh, (16) knee, (17) shank, and (18) foot. The number of areas with pain (range: 1-36) were summed. The PRI was measured at Pre-IMMPR. For descriptive purposes, self-reported pain duration (days) and persistent pain duration (days) are presented.

\section{Physical Activity Variables}

The SQRP includes two questions about physical activity (PA) based on the recommendation of the Swedish National Board of Health and Welfare. ${ }^{30}$ The questions are validated for use in Sweden: one about physical exercise every week (PE) and the one about everyday physical activity (EPA). ${ }^{31}$ The detailed calculation methods of PE time, EPA time, and total PA time have been described in a previous study. ${ }^{32}$ Briefly, during a regular week, selfperceived time spent on exercise that makes the person short winded (eg, running, fitness class, or ball games) was recognized as PE. The following answer alternatives were provided 0 minutes/none, less than 30 minutes, 30-60 minutes (0.5-1 hour), 60-90 minutes (1-1.5 hours), 90120 minutes (1.5-2 hours), and more than 120 minutes (2 hours). Second, during a regular week, self-perceived time on non-exercise physical activity (eg, walks, bicycling, or gardening) lasting for at least ten minutes was recognized as EPA. The following answer alternatives were provided 0 minutes/none, less than 30 minutes, $30-60$ minutes $(0.5-$ 1 hour), 60-90 minutes (1-1.5 hours), 90-150 minutes (1.5-2.5 hours), 150-300 minutes (2.5-5 hours), and more than 300 minutes (5 hours). Finally, the total PA time was calculated by multiplying PE by two and adding the product to EPA (PE minutes $\times 2+$ EPA minutes). The midpoints of intervals for each answer option were used (ie, less than 30 minutes converted to 15 minutes, 30-60 minutes converted to 45 minutes, more than 120 minutes or 300 minutes converted to 120 and 300 minutes, respectively).

\section{Psychological Variables}

The Insomnia Severity Index (ISI) includes seven items that generate a score between 0 and 28 that quantifies perceived insomnia severity. ${ }^{33,34}$ The reliability, validity, and clinical utility of the Swedish version of ISI have been previously studied. ${ }^{35-37}$

The Hospital Anxiety and Depression Scale (HADS) was used to measure anxiety and depression. ${ }^{38}$ HADS has two subscales - an anxiety subscale (HADS-A) and a depression subscale (HADS-D) - with a scoring range between 0 and 21. A higher score indicates a higher possibility of anxiety or depression. The Swedish translation of HADS has been validated. ${ }^{39}$ 
The Pain Catastrophizing Scale (PCS) measures catastrophic thinking related to pain. ${ }^{40}$ The PCS consists of 13 items in three domains: rumination, magnification, and helplessness. Each item has five answer alternatives on a five-point scale, ranging from 0 (not at all) to 4 (always). Patients assess the degree to which they experience certain thoughts or feelings during pain. Higher scores indicate a greater tendency for catastrophizing. The Swedish version of the PCS for patients with chronic pain has been validated. ${ }^{41}$ We use the total score $(0-52)$ in this study.

\section{HRQoL Variables}

Health-related Quality of Life (HRQoL) was measured using the RAND-36 (RAND Corporation, www.rand. org), which assesses multi-dimensional health concepts. ${ }^{42,43}$ RAND-36 has eight dimensions, each ranging from 0 to 100 . Two summary scores - physical and mental health composites (PCS and MCS) - are derived from these eight scales. We use both the PCS and MCS in this study.

\section{Statistics}

All statistics were performed using the statistical package IBM SPSS Statistics (version 26.0; IBM Corporation). Descriptive data include mean value with standard deviations (Mean $\pm \mathrm{SD}$ ) or median with interquartile range (IQR) for continuous variables and number with percentage $(\mathrm{n}, \%)$ for categorical variables. SQRP uses predetermined rules to handle single missing items of a scale or a subscale. This procedure has been reported elsewhere. ${ }^{44}$ To investigate within group changes at FU-IMMPR, we used paired sample $t$-test and Wilcoxon Signed-rank test to quantify the differences between Pre-IMMPR and FUIMMPR. Spearman correlations were calculated to test the linear relationship between weight changes, changes of pain intensity, and changes of other variables after IMMPR. A $p$ value below 0.05 was considered significant. Effect sizes (ES) for within-group analysis were computed using a calculator when appropriate (Cohen's $\mathrm{d}$ for $t$-test and $r$ for Wilcoxon signed-rank test). A summary of the ES interpretation is listed in Table $1 .^{45}$

To compare the impact of IMMPR to changes in the analysed variables between the three pain relief categories, we used linear mixed models to examine the influence of the main factors - ie, Group (groups with different levels of pain relief), Treatment (Pre-IMMPR and FU-IMMPR), and Group $\times$ Treatment interaction. Group x Treatment interaction indicated that group changes occurred as
Table I A Summary of Effect Size and Their Interpretations

\begin{tabular}{|l|c|c|}
\hline Interpretation & $\begin{array}{c}\text { Cohen's } \\
\text { d (t-test) }\end{array}$ & $\begin{array}{c}\mathbf{r} \text { (Wilcoxon Signed-Rank } \\
\text { Test) }\end{array}$ \\
\hline No Effect & 0.0 to $<0.20$ & 0.0 to $<0.10$ \\
Small Effect & 0.20 to $<0.50$ & 0.10 to $<0.30$ \\
Moderate Effect & 0.50 to $<0.80$ & 0.30 to $<0.50$ \\
Large Effect & $\geq 0.80$ & $\geq 0.50$ \\
\hline
\end{tabular}

Notes: Rules of thumb for interpreting effect sizes.

a consequence of IMMPR. Analysis of each variable of interest was adjusted for socio-demographic factors, change of pain intensity, and pain distribution.

\section{Results}

\section{General Characteristics, Changes in Weight, and Changes in Pain}

Of the 872 patients included in this study, 224 were classified as obese at Pre-IMMPR (224/872; 25.7\%). A summary of general characteristics is shown in Table 2. Most of the chronic pain patients with obesity were middle-aged women born in a Nordic country who had completed secondary school education. A significant higher proportion were working or studying at FUIMMPR but not at Pre-IMMPR $(72.3 \%$ vs $51.3 \%, p<$ 0.01, small ES).

Of the 224 patients classified as obese at admission, most were classified as class I (71.9\%) or class II (20.5\%). The absolute values of weight change and BMI change were non-significant from Pre-IMMPR to FU-IMMPR. At FU-IMMPR, over one-fifth (21.3\%) of the patients had reached $\geq 5 \%$ weight loss.

In this study, most participants had a high pain intensity (ie, NRS $=7-10)$ at Pre-IMMPR (140/223; 62.5\%). A significant reduction of pain intensity was found at FUIMMPR $(p<0.01 ; \mathrm{ES}=0.34$; small ES) (Table 2). One-fifth of the patients achieved pain relief of clinical importance (NRS decrease at least 30\%) and one-fourth had pain relief but it did not reach clinical importance (Table 3). A widespread pain distribution (PRI, $17 \pm 9$ ) with long pain duration (median years: 7.9) and persistent pain (median years: 5) was found in the sample.

No statistically significant difference was noted for weight, BMI, and pain intensity at Pre-IMMPR between the patients with complete information on weight and pain status at FU-IMMPR and dropouts $(\mathrm{n}=44$, data not shown). 
Table 2 General Characteristics of Obese Patients $(N=224)$

\begin{tabular}{|c|c|}
\hline Characteristics & Total n (\%) \\
\hline \multicolumn{2}{|l|}{ Sociodemographic variables } \\
\hline Age, Mean \pm SD & $46.8 \pm 8.2$ \\
\hline Gender (female) & $177(82.3)$ \\
\hline Place of birth (Nordic countries) & $187(87.3)$ \\
\hline \multicolumn{2}{|l|}{ Education } \\
\hline College/university & $55(3 I .8)$ \\
\hline Secondary school & $94(54.3)$ \\
\hline Primary school & $24(13.9)$ \\
\hline \multicolumn{2}{|l|}{ Working/ study } \\
\hline Pre-IMMPR & $115(51.3)$ \\
\hline FU-IMMPR & $162(72.3)^{\mathrm{a}}$ \\
\hline \multicolumn{2}{|l|}{ Body weight } \\
\hline \multicolumn{2}{|l|}{ Weight, Mean \pm SD } \\
\hline Pre-IMMPR & $97.2 \pm 16.0$ \\
\hline FU-IMMPR $(n=183)$ & $95.9 \pm 17.4^{b}$ \\
\hline \multicolumn{2}{|l|}{ BMI, Mean \pm SD } \\
\hline Pre-IMMPR & $34.2 \pm 4.0$ \\
\hline FU-IMMPR $(n=183)$ & $33.6 \pm 4.3^{b}$ \\
\hline \multicolumn{2}{|l|}{ BMI category at Pre-IMMPR, n (\%) } \\
\hline Obesity class I & I6I (7I.9) \\
\hline Obesity class II & $46(20.5)$ \\
\hline Obesity class III & $17(7.6)$ \\
\hline \multicolumn{2}{|l|}{ Pain features } \\
\hline \multicolumn{2}{|l|}{ Pain intensity, NRS-7d, Mean \pm SD } \\
\hline Pre-IMMPR $(\mathrm{n}=223)$ & $6.9 \pm 1.7$ \\
\hline FU-IMMPR ( $n=216)$ & $6.2 \pm 2.2^{c}$ \\
\hline Pain Regional Index $(n=223)$, Mean \pm SD & $17 \pm 9$ \\
\hline Pain duration, days, Median ( $q \mathrm{I}-\mathrm{q} 3$ ) & $2878(949-6708)$ \\
\hline Persistent pain duration, days, Median ( $q \mathrm{I}-\mathrm{q} 3$ ) & $1832(7 \mid 8-6036)$ \\
\hline
\end{tabular}

Notes: ${ }^{a} p<0.01$, ES $=0.22$; ${ }^{b} p>0.05$, ES $<0.30 ;{ }^{c} p<0.01$, ES $=0.34$.

Abbreviation: ES, effect size.

\section{Relationship Between Weight Change and Pain Change}

A similar proportion of patients reached at least $5 \%$ weight loss in the three categories of pain relief $\left(\mathrm{Chi}^{2}=3.524, d f\right.$ $=4, p=0.47$, Table 3 ). No significant change was found in absolute weight values from Pre-IMMPR to FU-IMMPR between the three categories of pain relief nor in each category (Cohen's $d=0.07-0.23$ ) (Figure 1 and Table 4).

\section{Relationship Between the Improvements at IMMPR and Weight Changes}

Change in body weight only positively correlated with change in PCS (Spearman's rho $=0.173$ ) (Table 5). Change of pain intensity had weak correlations (Spearman's rho $=0.26-0.35$ ) with improvements in some psychological profiles as well as HRQoL, but change of pain intensity did not correlate with weight change, other pain aspects, nor changes in the amount of physical activities (Table 5).

Compared to the group with pain relief of clinical importance, the other two groups had significantly higher psychological distress (HADS-A, HADS-D, ISI, and PCS) and lower HRQoL (Rand 36) at FU-IMMPR (Table 4). The group differences at Pre-IMMPR were only noted in HADS-A, ISI, and the two summary scores of Rand 36. Within each group of different pain relief levels, significant differences (small to large ES) were noted after IMMPR in the improvement of physical activity, psychological distress, and HRQoL. The group with pain relief of clinical importance had greater improvements (larger ES) than the other two groups except the change of total PA time.

Linear mixed regression analysis showed significant effects of IMMPR ( $\mathrm{F}=6.13 \sim 77.75, p<0.01)$ on improvements of physical activity, psychological distress, and HRQoL (Table 4). After adjustment for background variables, changes of pain intensity, and pain distribution, the significant changes among the groups due to IMMPR were shown in psychological distress as well as HRQoL (Group $\mathrm{x}$ IMMPR interactions, $\mathrm{F}=4.39 \sim 14.03, p<0.05$ ). However, there were no significant effects of group, IMMPR, or Group x IMMPR factor interaction on weight change or BMI change.

\section{Discussion}

To the best of our knowledge, this is the first study reporting body weight changes after IMMPR for chronic pain patients with comorbid obesity in pain rehabilitation clinics. The current IMMPR had improvements in many aspects (ie, pain intensity, physical exercises, psychosocial well-beings, and HRQoL) but was not always effective in weight reduction for patients with obesity. As with the previous studies, ${ }^{15,46,47}$ we are aware that it is difficult to 
Table 3 Weight Changes Among the Groups with Different Pain Relief at FU-IMMPR

\begin{tabular}{|c|c|c|c|c|c|}
\hline $\begin{array}{l}\text { Pain Relief } \\
\text { Weight Change }\end{array}$ & $\begin{array}{c}\text { Total } \\
(n=180)\end{array}$ & $\begin{array}{c}\text { Pain Relief } \geq \mathbf{3 0} \% \text { NRS } \\
\text { Decrease }\end{array}$ & $\begin{array}{c}\text { Pain Relief }<30 \% \text { NRS } \\
\text { Decrease }\end{array}$ & $\begin{array}{c}\text { No Pain } \\
\text { Relief }\end{array}$ & P-value \\
\hline Weight gainers & $27(15)$ & $4(10.8)$ & II (22.4) & $12(12.8)$ & 0.47 \\
\hline Weight stable & II4 (63.3) & $24(64.9)$ & $27(55.1)$ & $63(67)$ & \\
\hline Weight losers & $39(21.7)$ & $9(24.3)$ & II (22.4) & $19(20.2)$ & \\
\hline
\end{tabular}

Notes: Statistics, $\mathrm{Chi}^{2}=3.524, \mathrm{df}=4$.

target obesity and chronic pain simultaneously. Since emerging evidence suggests weight reduction can alleviate pain and pain-related functional impairment, ${ }^{48,49}$ a more integrated program with a goal of weight loss should be considered in pain rehabilitation for obese patients.

\section{Did Obese Patients Lose Weight After IMMPR?}

No statistically significant difference in weight change or BMI change was found at FU-IMMPR among the obese patients. However, about one-fifth of the obese patients had achieved weight reduction of clinical significance at FU-IMMPR despite the fact that weight reduction is not considered a main goal in IMMPR. Our study had fewer weight losers compared to studies assessing traditional weight management programs. ${ }^{4,5}$ In addition to a relative lower baseline BMI than the patients included in weight management programs, one pronounced difference in our study was that our patients had more severe pain aspects, such as high baseline pain intensity, widespread pain distribution, and long persistent pain duration.

\section{Relationship Between Weight Change and Pain Change}

Reduction of pain intensity was statistically significant at FU-IMMPR among the obese patients. However, there were no significant weight changes in obese patients who reported reduction of pain nor in obese patients who did not report reduction of pain, findings that suggest that pain reduction was unrelated to weight reduction. Within each pain relief level, no significant weight change was evident. Obesity modulates pain in several ways, such as through mechanical

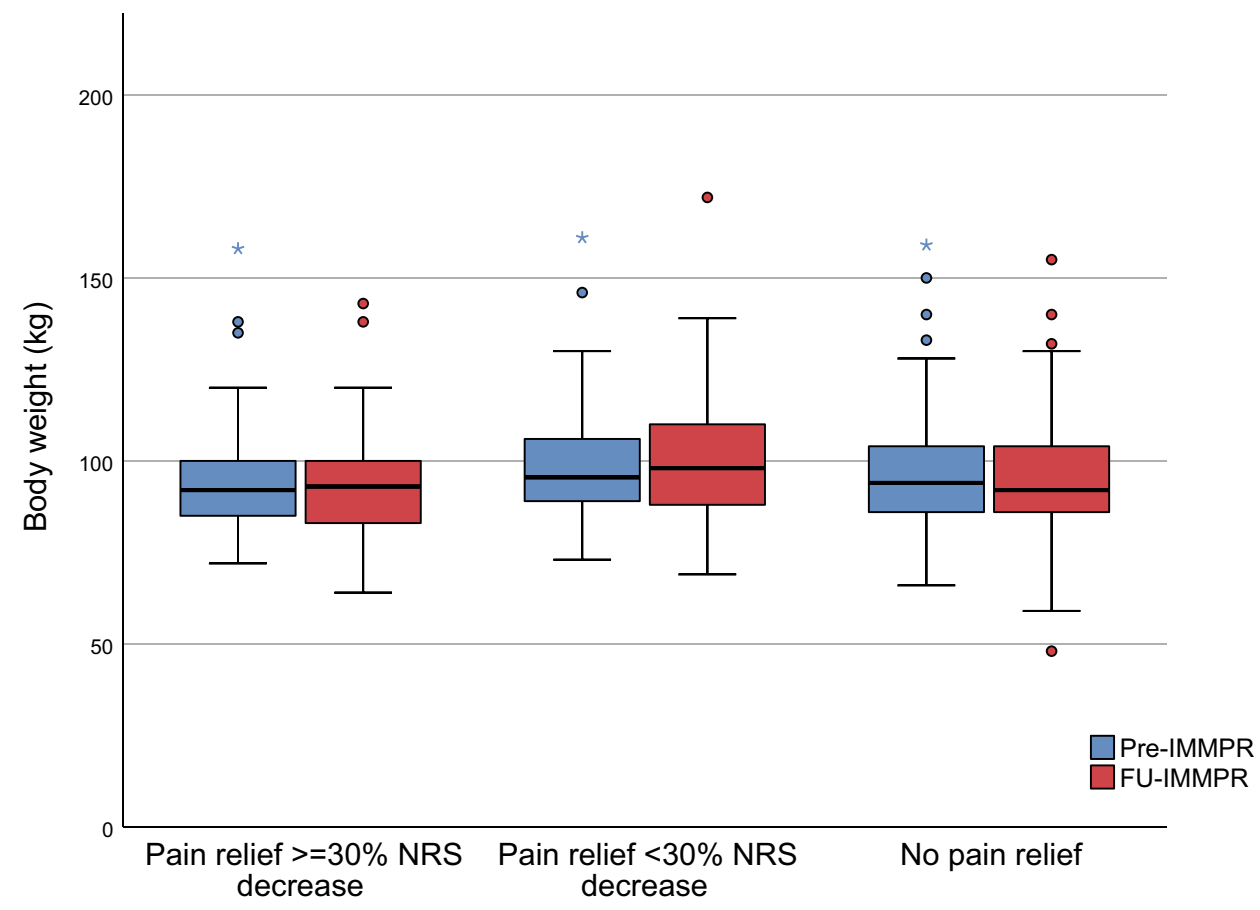

Figure I Body weight for the three categories of pain relief. The boundary of the box closest to zero indicates the 25 th percentile, a black line within the box marks the median, and the boundary of the box farthest from zero indicates the 75 th percentile. Whiskers above and below the box indicate the error bars ( $95 \%$ confidence intervals). Mild outliers are marked with a circle $(\mathrm{O})$ and extreme outliers are marked with an asterisk $(*)$. 


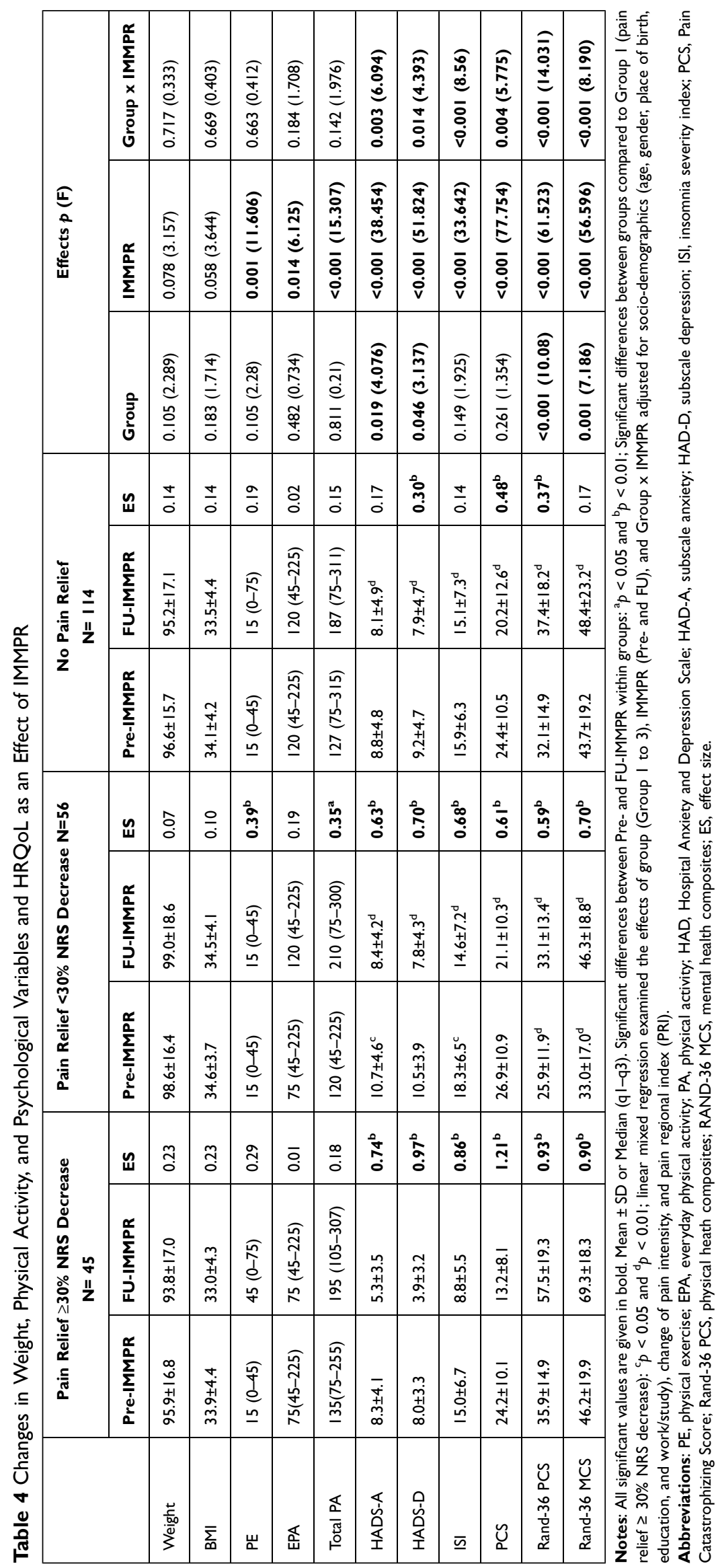


Table 5 Spearman Correlations of Changes in Body Weight, Pain Intensity, and Other Outcomes After IMMPR

\begin{tabular}{|l|c|c|}
\hline Variables & $\Delta$ Body Weight & $\Delta$ Pain Intensity (NRS-7d) \\
\hline$\Delta$ Body Weight & - & 0.095 \\
$\Delta$ Pain intensity (NRS-7d) & 0.095 & - \\
Pain duration, days & -0.069 & -004 \\
Pain-persistent- duration & -0.048 & -0.023 \\
Pain Region Index & -0.062 & -0.065 \\
$\Delta$ Physical exercise time per week & -0.090 & -0.122 \\
$\Delta$ Everyday PA time per week & -0.101 & -0.074 \\
$\Delta$ Total PA time per week & -0.102 & -0.124 \\
$\Delta$ HADS-Anxiety & -0.016 & $0.284^{\mathrm{b}}$ \\
$\Delta$ HADS-Depression & -0.035 & $0.260^{\mathrm{b}}$ \\
$\Delta$ Insomnia Severity Index & -0.038 & $0.318^{\mathrm{b}}$ \\
$\Delta$ Pain Catastrophizing Score & $0.173^{\mathrm{a}}$ & $0.258^{\mathrm{b}}$ \\
$\Delta$ Rand-36 PCS & -0.054 & $-0.343^{\mathrm{b}}$ \\
$\Delta$ Rand-36 MCS & 0.028 & $-0.351^{\mathrm{b}}$ \\
\hline
\end{tabular}

Notes: $\Delta=$ difference between Pre-IMMPR and FU-IMMPR. ${ }^{\mathrm{a}} p<0.05,{ }^{\mathrm{b}} p<0.01$.

Abbreviations: PA, physical activity; HAD, Hospital Anxiety and Depression Scale; HAD-A, subscale anxiety; HAD-D, subscale depression; Rand-36 PCS, physical heath composites; RAND-36 MCS, mental health composites.

loading, ${ }^{50}$ proinflammatory cytokines, ${ }^{51,52}$ and psychological strain. ${ }^{53,54}$ Previous qualitative studies demonstrate that obese patients are aware of the relationship between chronic pain and their weight problem. ${ }^{16,47}$ Simultaneous improvement should be expected when either condition is treated. However, a recent systematic review demonstrated a trivial relationship of weight loss and pain relief after completing a weight management program. ${ }^{15}$ This study quantified the effects of weight reduction interventions on both weight loss and pain relief for patients with these two comorbidities. As with these previous studies, our findings showed no significant overall relationship between weight loss and pain relief after IMMPR in obese patients with chronic pain. Moreover, we were unable to correlate weight change with other measured improvements after IMMRP at follow-up (Table 5). Together with the previous studies' results about weight management services, our findings suggest future pain rehabilitation programs should incorporate both weight reduction and pain interventions for patients with the two comorbidities.

\section{Relationship Between Weight Change and Other Improvements After IMMPR}

Other factors closely related to weight control - eg, physical activity behaviour, psychological distress, and HRQoL were significantly improved in the obese patients at FUIMMPR. Most notably, regardless of the level of pain relief, the obese patients had significant improvements in depression, pain catastrophizing, and physical health. These results suggest that IMMPR can help obese patients address their weight management challenges (inactive lifestyle, increased eating, etc.). ${ }^{2,6,16,55-57}$ Significant effects of interactions of Group x IMMPR reflected that IMMPR and pain relief levels affected improvements in psychological distress and HRQoL. However, the varied improvements of physical activity behaviour among the groups confirm the complexity of the impacts on this lifestyle behaviour. ${ }^{32}$ As adherence to exercise is difficult for obese people, ${ }^{9}$ perhaps healthcare providers need access to interventions other than those included in current IMMPR to improve physical activity and weight control for obese patients.

\section{Clinical Implications and Future Research}

Since obesity is a risk factor for developing chronic pain and vice versa, ${ }^{8,9}$ a routine screening of the weight status and obesity-related medical conditions is included in pain rehabilitation practices. The complex clinical presentation of disabling pain indicates that no one intervention, either pharmacological/surgical or non-pharmacological, can tackle the consequences of chronic pain, such as sick leave, experiencing major interference in daily life, and chronic disability.

The need for simultaneous treatment of obesity and pain has already been highlighted. ${ }^{46,48}$ Unlike weight management programs, an interdisciplinary rehabilitation team of IMMPRs typically do not include a dietitian, an essential resource for patients who need help with weight control. Dietary intervention is crucial for weight loss, weight maintenance, and pain relief. ${ }^{47,49,58}$ A future integrated pain 
rehabilitation program should consider this aspect for patients with comorbid obesity. Second, scheduled daily physical activities can be encouraged before making great efforts to increase physical exercises. ${ }^{59}$ Third, psychological intervention on eating behaviour should be considered as much evidence has shown significant influences of pain inducing greater energy intake. ${ }^{7}$ Interventions that target weight reduction in pain rehabilitation may increase the possibility of weight changes, and this can affect the association to pain relief. Well-designed and high-quality RCTs are needed to examine whether one or more interventions integrated with IMMPR can simultaneously reduce pain and weight. Moreover, future IMMPR research on specific patient categories based on pain conditions (eg, fibromyalgia and low back pain) is particularly valuable due to the large populations in primary care as well as in community dwellings.

This study has several limitations. Although we used a feasible dataset registered for pain rehabilitation clinics, we did not have information about whether the patients received other weight management interventions during the follow-up period (12 months after IMMPR completed). Second, we did not analyse pharmacological treatment on chronic pain since some medications could negatively affect weight reduction. Third, we used ISI to assess insomnia in IMMPR, but we neglected the possible influence of another pain and obesity-linked sleep disturbance - ie, obstructive sleep apnoea. ${ }^{60,61}$ It is unknown whether a lack of improvement among the patients without pain relief after IMMPR was mediated by the existing comorbidity. Fragmented sleep is common in both chronic pain and obstructive sleep apnoea. ${ }^{1,62}$ As adequate treatment of obstructive sleep apnoea may contribute to pain relief, ${ }^{62}$ obese patients should be screened for sleep apnoea and optimising interventions should be included before IMMPR. ${ }^{60,62}$ Finally, the generalisation of the study results is limited to the obese patients with complex chronic pain referred to specialist pain rehabilitation clinics. However, our findings provide a great potential to improve IMMPR in both daily clinical practice and future pain rehabilitation research.

\section{Conclusion}

About one-fifth of obese chronic patients achieved significant weight reduction after IMMPR. The current pain rehabilitation programs (IMMPRs) displayed significant improvement in many aspects (ie, pain intensity, physical activity behaviour, psychosocial distress, and HRQoL), but they were ineffective in weight reduction for the majority of patients with obesity. Especially for the patients with obesity, future IMMPRs should consider incorporating a target approach for weight management.

\section{Data Sharing Statement}

The datasets generated and analysed in this study are not publicly available as the Ethical Review Board has not approved the public availability of these data.

\section{Acknowledgments}

The authors thank all the participants. This study was supported by grants from the County Council of Östergötland (Research-ALF, LIO-608021 and SC-2017-00202-28). The funders had no role in study design, data collection, data analysis, data interpretation, writing of the report, or the decision to submit for publication. The authors had full access to all the data in the study and had final responsibility for the decision to submit for publication.

\section{Author Contributions}

All authors made a significant contribution to the work reported, whether that is in the conception, study design, execution, acquisition of data, analysis and interpretation, or in all these areas; took part in drafting, revising or critically reviewing the article; gave final approval of the version to be published; have agreed on the journal to which the article has been submitted; and agree to be accountable for all aspects of the work.

\section{Disclosure}

The authors declare no conflicts of interest.

\section{References}

1. Okifuji A, Hare BD. The association between chronic pain and obesity. J Pain Res. 2015;8:399-408. doi:10.2147/JPR.S55598

2. McVinnie DS. Obesity and pain. Br J Pain. 2013;7(4):163-170. doi: $10.1177 / 2049463713484296$

3. Masheb RM, Lutes LD, Kim HM, et al. Weight loss outcomes in patients with pain. Obesity. 2015;23(9):1778-1784. doi:10.1002/ oby. 21160

4. Ryan CG, Vijayaraman A, Denny V, et al. The association between baseline persistent pain and weight change in patients attending a specialist weight management service. PLoS One. 2017;12(6): e0179227. doi:10.1371/journal.pone.0179227

5. Dunlevy C, MacLellan GA, O’Malley E, et al. Does changing weight change pain? Retrospective data analysis from a national multidisciplinary weight management service. Eur J Pain. 2019;23 (8):1403-1415. doi:10.1002/ejp.1397

6. Somers TJ, Blumenthal JA, Guilak F, et al. Pain coping skills training and lifestyle behavioral weight management in patients with knee osteoarthritis: a randomized controlled study. Pain. 2012;153 (6):1199-1209. doi:10.1016/j.pain.2012.02.023 
7. Chin SH, Huang WL, Akter S, Binks M. Obesity and pain: a systematic review. Int $J$ Obes. 2020;44(5):969-979. doi:10.1038/ s41366-019-0505-y

8. Arranz LI, Rafecas M, Alegre C. Effects of obesity on function and quality of life in chronic pain conditions. Curr Rheumatol Rep. 2014;16(1):390. doi:10.1007/s11926-013-0390-7

9. Zdziarski LA, Wasser JG, Vincent HK. Chronic pain management in the obese patient: a focused review of key challenges and potential exercise solutions. J Pain Res. 2015;8:63-77. doi:10.2147/JPR. S55360

10. Dong HJ, Larsson B, Rivano Fischer M, Gerdle B. Maintenance of quality of life improvement for patients with chronic pain and obesity after interdisciplinary multimodal pain rehabilitation - a study using the Swedish quality registry for pain rehabilitation. Eur J Pain. 2019;23(10):1839-1849. doi:10.1002/ejp.1457

11. Ringqvist A, Dragioti E, Bjork M, Larsson B, Gerdle B. Moderate and stable pain reductions as a result of interdisciplinary pain rehabilitation-a Cohort Study from the Swedish Quality Registry for Pain Rehabilitation (SQRP). J Clin Med. 2019;8(6). doi:10.3390/ jem8060905

12. Bennett MCS. Methodological issues in nonpharamacological trials for chronic pain. Pain. 2010;18:1-6.

13. Turk DC, Wilson H, Swanson KS. The biopsychosocial model of pain and pain management. In: Ebert MH, Kerns RD, editors. Behavioral and Psychopharmacologic Pain Management. Cambridge University Press; 2011:16-43.

14. Huang MH, Chen $\mathrm{CH}$, Chen TW, Weng MC, Wang WT, Wang YL. The effects of weight reduction on the rehabilitation of patients with knee osteoarthritis and obesity. Arthritis Care Res. 2000;13 (6):398-405 . doi:10.1002/1529-0131(200012)13:6<398::AIDART10>3.0.CO;2-E

15. Cooper L, Ryan CG, Ells LJ, et al. Weight loss interventions for adults with overweight/obesity and chronic musculoskeletal pain: a mixed methods systematic review. Obes Rev. 2018;19 (7):989-1007. doi:10.1111/obr.12686

16. Cooper L, Ells L, Ryan C, Martin D. Perceptions of adults with overweight/obesity and chronic musculoskeletal pain: an interpretative phenomenological analysis. J Clin Nurs. 2018;27(5-6):e776e786. doi:10.1111/jocn.14178

17. Tseli E, LoMartire R, Vixner L, Grooten WJA, Gerdle B, Ang BO. What is the effectiveness of different duration interdisciplinary treatment programs in patients with chronic pain? A Large-Scale Longitudinal Register Study. J Clin Med. 2020;9:9. doi:10.3390/ jcm9092788

18. SBU. Rehabilitation of chronic pain (In Swedish: rehabilitering vid långvarig smärta. En systematisk litteraturöversikt). SBU-rapport; 2010. Available from: http://www.sbu.se/rehab_langvarig_smarta. Accessed June 8, 2021.

19. Casey MB, Smart KM, Segurado R, Doody C. Multidisciplinarybased Rehabilitation (MBR) compared with active physical interventions for pain and disability in adults with chronic pain: a systematic review and meta-analysis. Clin J Pain. 2020;36(11):874-886. doi:10.1097/AJP.0000000000000871

20. Scascighini L, Toma V, Dober-Spielmann S, Sprott H. Multidisciplinary treatment for chronic pain: a systematic review of interventions and outcomes. Rheumatology. 2008;47(5):670-678. doi:10.1093/rheumatology/ken021

21. WHO. Obesity: Preventing and Managing the Global Epidemic: Report of a WHO Consultation. Geneva: World Health Organization; 2000.

22. Brown TJ, O'Malley C, Blackshaw J, et al. Exploring the evidence base for tier 3 weight management interventions for adults: a systematic review. Clin Obes. 2017;7(5):260-272. doi:10.1111/ cob. 12204
23. Williamson DA, Bray GA, Ryan DH. Is $5 \%$ weight loss a satisfactory criterion to define clinically significant weight loss? Obesity. 2015;23 (12):2319-2320. doi:10.1002/oby.21358

24. Jensen MD, Ryan DH, Apovian CM, et al. 2013 AHA/ACC/TOS guideline for the management of overweight and obesity in adults: a report of the American College of Cardiology/American Heart Association Task Force on Practice Guidelines and The Obesity Society. Circulation. 2014;129(25 Suppl 2):S102-S138. doi:10.1161/01.cir.0000437739.71477.ee

25. Kuczmarski MF, Kuczmarski RJ, Najjar M. Effects of age on validity of self-reported height, weight, and body mass index: findings from the Third National Health and Nutrition Examination Survey, 19881994. J Am Diet Assoc. 2001;101(1):28-34; quiz 35-26. doi:10.1016/ S0002-8223(01)00008-6

26. Vuksanović M, Safer A, Palm F, Stieglbauer G, Grau A, Becher H. Validity of self-reported BMI in older adults and an adjustment model. J Public Health (Bangkok). 2014;22(3):257-263. doi:10.1007/s10389-014-0619-6

27. Farrar JT, Young JP Jr, LaMoreaux L, Werth JL, Poole MR. Clinical importance of changes in chronic pain intensity measured on an 11-point numerical pain rating scale. Pain. 2001;94(2):149-158. doi:10.1016/S0304-3959(01)00349-9

28. Breivik H, Borchgrevink PC, Allen SM, et al. Assessment of pain. $\mathrm{Br}$ $J$ Anaesth. 2008;101(1):17-24. doi:10.1093/bja/aen103

29. Salaffi F, Stancati A, Silvestri CA, Ciapetti A, Grassi W. Minimal clinically important changes in chronic musculoskeletal pain intensity measured on a numerical rating scale. Eur J Pain. 2004;8 (4):283-291. doi:10.1016/j.ejpain.2003.09.004

30. The Swedish National Board of Health and Welfare. Disease Prevention in the Swedish Healthcare System: Health Situation, National Guidelines and Implementation, Indicators, Appendix (In Swedish: Nationella Riktlinjer För Sjukdomsförebyggande Metoder 2011, Indikatorer, Bilaga); 2013.

31. The Public Health Agency of Sweden. Aim and background to the questions in national public health survey. Health on equal terms 2018 (In Swedish: syfte och bakgrund till frågorna i den nationella folkhälsoenkäten. Hälsa på lika villkor 2018); 2018. Available from: https://www.folkhalsomyndigheten.se/publicerat-material/. Accessed June 8, 2021.

32. Dong HJ, Larsson B, Rivano Fischer M, Gerdle B. Facing obesity in pain rehabilitation clinics: profiles of physical activity in patients with chronic pain and obesity-A study from the Swedish Quality Registry for Pain Rehabilitation (SQRP). PLoS One. 2020;15(9): e0239818. doi:10.1371/journal.pone.0239818

33. Morin CM, Belleville G, Belanger L, Ivers H. The insomnia severity index: psychometric indicators to detect insomnia cases and evaluate treatment response. Sleep. 2011;34(5):601-608. doi:10.1093/sleep/ 34.5.601

34. Bastien $\mathrm{CH}$, Vallieres A, Morin CM. Validation of the insomnia severity index as an outcome measure for insomnia research. Sleep Med. 2001;2(4):297-307. doi:10.1016/S1389-9457(00)00065-4

35. Trott E. Reliability and Validity of the Swedish Version of Insomnia Severity Index (ISI) (In Swedish: En reliabilitets- och validitetsstudie av den svenska versionen av självskattningsformuläret Insomnia Severity Index) [Student thesis]. 2009. Available from: http://urn.kb. se/resolve?urn=urn:nbn:se:su:diva-28468. Accessed June 8, 2021.

36. Dragioti E, Wiklund T, Alfoldi P, Gerdle B. The Swedish version of the insomnia severity index: factor structure analysis and psychometric properties in chronic pain patients. Scand J Pain. 2015;9 (1):22-27. doi:10.1016/j.sjpain.2015.06.001

37. Alfoldi P, Wiklund T, Gerdle B. Comorbid insomnia in patients with chronic pain: a study based on the Swedish quality registry for pain rehabilitation (SQRP). Disabil Rehabil. 2014;36(20):1661-1669. doi:10.3109/09638288.2013.864712 
38. Zigmond AS, Snaith RP. The hospital anxiety and depression scale. Acta Psychiatr Scand. 1983;67(6):361-370. doi:10.1111/j.16000447.1983.tb09716.x

39. Lisspers J, Nygren A, Soderman E. Hospital Anxiety and Depression Scale (HAD): some psychometric data for a Swedish sample. Acta Psychiatr Scand. 1997;96(4):281-286. doi:10.1111/j.16000447.1997.tb10164.x

40. Sullivan MJL, Bishop SR, Pivik J. The pain catastrophizing scale: development and validation. Psychol Assess. 1995;7(4):524-532. doi:10.1037/1040-3590.7.4.524

41. Karlsson $\mathrm{C}$, Linderoth $\mathrm{K}$ Svensk validering av pain catastrophizing scale samt sambanden mellan smärtkatastrofiering, sömnproblem och ångest respektive depression. 2018.

42. Hays RD, Morales LS. The RAND-36 measure of health-related quality of life. Ann Med. 2001;33(5):350-357. doi:10.3109/ 07853890109002089

43. Hays RD, Sherbourne CD, Mazel RM. The RAND 36-item health survey 1.0. Health Econ. 1993;2(3):217-227. doi:10.1002/ hec. 4730020305

44. Gerdle B, Molander P, Stenberg G, Stalnacke BM, Enthoven P. Weak outcome predictors of multimodal rehabilitation at one-year follow-up in patients with chronic pain-a practice based evidence study from two SQRP centres. BMC Musculoskelet Disord. 2016;17 (1):490. doi:10.1186/s12891-016-1346-7

45. Cohen J. Statistical Power Analysis for the Behavior Sciences. 2 ed. Lawrence Erlbaum Associates; 1988:283.

46. Janke EA, Fritz M, Hopkins C, Haltzman B, Sautter JM, Ramirez ML. A randomized clinical trial of an integrated behavioral self-management intervention simultaneously targeting obesity and pain: the STOP trial. BMC Public Health. 2014;14(1):621. doi:10.1186/1471-2458-14-621

47. Amy janke E, Kozak AT. "The more pain I have, the more I want to eat": obesity in the context of chronic pain. Obesity. 2012;20 (10):2027-2034. doi:10.1038/oby.2012.39

48. Narouze S, Souzdalnitski D. Obesity and chronic pain: systematic review of prevalence and implications for pain practice. Reg Anesth Pain Med. 2015;40(2):91-111. doi:10.1097/AAP.0000000000000218

49. Brain K, Burrows TL, Rollo ME, et al. A systematic review and meta-analysis of nutrition interventions for chronic noncancer pain. J Hum Nutr Diet. 2019;32(2):198-225. doi:10.1111/jhn.12601

50. Wearing SC, Hennig EM, Byrne NM, Steele JR, Hills AP. Musculoskeletal disorders associated with obesity: a biomechanical perspective. Obes Rev. 2006;7(3):239-250. doi:10.1111/j.1467789X.2006.00251.x
51. Hauner H. Secretory factors from human adipose tissue and their functional role. Proc Nutr Soc. 2005;64(2):163-169. doi:10.1079/ PNS2005428

52. Bas S, Finckh A, Puskas GJ, et al. Adipokines correlate with pain in lower limb osteoarthritis: different associations in hip and knee. Int Orthop. 2014;38(12):2577-2583. doi:10.1007/s00264-014-2416-9

53. Li JX. Pain and depression comorbidity: a preclinical perspective. Behav Brain Res. 2015;276:92-98. doi:10.1016/j.bbr.2014.04.042

54. Okifuji A, Turk DC. Chronic pain and depression: vulnerability and resilience. In: Flaten MA, al'Absi M, editor. Neuroscience of Pain, Stress, and Emotion. Elsevier; 2016:181-201.

55. Bond DS, Buse DC, Lipton RB, et al. Clinical pain catastrophizing in women with migraine and obesity. Headache. 2015;55(7):923-933. doi: $10.1111 /$ head.12597

56. Hauser W, Schmutzer G, Brahler E, Schiltenwolf M, Hilbert A. The impact of body weight and depression on low back pain in a representative population sample. Pain Med. 2014;15 (8):1316-1327. doi:10.1111/pme.12458

57. Schwarze M, Hauser W, Schmutzer G, Brahler E, Beckmann NA, Schiltenwolf M. Obesity, depression and hip pain. Musculoskelet Care. 2019;17(1):126-132. doi:10.1002/msc.1380

58. Jennings A, Hughes CA, Kumaravel B, et al. Evaluation of a multidisciplinary tier 3 weight management service for adults with morbid obesity, or obesity and comorbidities, based in primary care. Clin Obes. 2014;4(5):254-266. doi:10.1111/cob.12066

59. Fontaine KR, Conn L, Clauw DJ. Effects of lifestyle physical activity on perceived symptoms and physical function in adults with fibromyalgia: results of a randomized trial. Arthritis Res Ther. 2010;12(2): R55. doi:10.1186/ar2967

60. Frange C, Naufel MF, Coelho FMS. Weight management and musculoskeletal pain: does sleep mediate the connection?: "Does changing weight change pain? Retrospective data analysis from a national multidisciplinary weight management service.”. Eur J Pain. 2019;23 (8):1578-1579. doi:10.1002/ejp.1440

61. Sweetman A, Lack L, McEvoy D. Refining the measurement of insomnia in patients with obstructive sleep apnea. J Clin Sleep Med. 2019;15(12):1717-1719. doi:10.5664/jcsm.8108

62. Charokopos A, Card ME, Gunderson C, Steffens C, Bastian LA. The association of obstructive sleep apnea and pain outcomes in adults: a systematic review. Pain Med. 2018;19(suppl_1):S69-S75. doi:10.1093/pm/pny140
Journal of Pain Research

\section{Publish your work in this journal}

The Journal of Pain Research is an international, peer reviewed, open access, online journal that welcomes laboratory and clinical findings in the fields of pain research and the prevention and management of pain. Original research, reviews, symposium reports, hypothesis formation and commentaries are all considered for publication. The manuscript

Submit your manuscript here: https://www.dovepress.com/journal-of-pain-research-journa management system is completely online and includes a very quick and fair peer-review system, which is all easy to use. Visit http:// www.dovepress.com/testimonials.php to read real quotes from published authors. 